\title{
Exploring Ecological Interface Design for Future ROV Capabilities in Maritime Command and Control
}

\author{
Daniel Fay ${ }^{1}$, Aaron PJ Roberts ${ }^{1}$, Neville Stanton ${ }^{1}$ \\ ${ }^{1}$ Human Factors Engineering, Transportation Research Group, Civil, Maritime and Envi- \\ ronmental Engineering and Sciences, Faculty of Engineering and the Environment, Boldrewood \\ Innovation Campus, University of Southampton, Burgess Road, Southampton, SO16 7QF, \\ United Kingdom
}

\{D.T.Fay, apr1c13, N.Stanton\}@southampton.ac.uk

\begin{abstract}
Future maritime command teams will process more data, a trend driven by continued technological advances and new sensors. Remotely Operated Vehicles (ROVs) are contributing to this, as their usage is steadily growing in civilian and military contexts. A key challenge is effective integration of growing volumes of data into the command team, ensuring optimal performance for completing the variety of missions and tasks that may be required. In particular, operator cognitive capacity should not be exceeded, as this may negatively impact global team performance. A review of ROV usage revealed that they are predominately deployed to understand and interact with their environment. Ecological Interface Design (EID) aims to make system constraints apparent and reduce operator workload. As the aims of EID are synergistic with ROV operation, it is hypothesised that operator workload may be reduced if interfaces are implemented that adhere to these design principles. In the current work EID is proposed as a design paradigm for ROV UIs, to facilitate optimal future performance.
\end{abstract}

Keywords: Maritime command teams $\cdot$ Remotely Operated Vehicles $\cdot$ Ecological Interface Design

\section{Introduction}

Interest in Unmanned Underwater Vehicles (UUV) is growing, as they permit completion of tasks that may be dangerous, or beyond human capability, to be achieved safely. Tasks for which UUVs are currently used include search and rescue, monitoring undersea infrastructure, mine hunting, and training [1-3]. However, navies are aiming to expand their usage for a variety of mission types, ranging from Intelligence, Surveillance, and Reconnaissance (ISR) to Information Operations (IO) [4-8]. This additional usage is contributing to maritime command teams of the future being required to process more data, and has the potential to cognitively overload operators if effective systems are not designed [9]. In the aviation domain, Human Factors issues have been found to be a contributory factor in several incidents involving Unmanned Air Vehicles (crashes, landing accidents, etc.) across the US Army, Navy, 
and Air Force [10]. It is argued that these incidents could be attributed to high cognitive demands, and reduced Situational Awareness (SA) of operators [11]. While the maritime domain poses unique Human Factors challenges, such as limited visibility or poor robotic control [12], issues as a result of high cognitive demand and reduced SA could still be present. Thus, the operation and management of data collected by UUVs is an area warranting further investigation to maximise utility and maintain operator workload at optimal levels.

UUV types can be split into two main categories, Remotely Operated Vehicles (ROVs) and Autonomous Underwater Vehicles (AUVs) [13, 14]. ROVs are connected to ownship via a tether, and receive constant manual input from operators [14]. There are two main types of tether in the maritime domain, copper and fibre. Copper tethers are commonplace, although may be ineffective due to their heaviness, and limited bandwidth [15]. Fibre tethers overcome these problems, but may be less robust than copper $[15,16]$. Conversely, AUVs are not connected to ownship, and will execute their actions autonomously, according to preprogramed goals [17]. Communication with ownship may be possible, although there may be problems with throughput, speed, or transmission distance, due to the medium [18]. This paper will focus on ROVs, as they have the most communication between human and machine, and therefore are most pertinent for Human-Machine Interaction (HMI) investigation. However, for the purpose of completeness, AUVs, where relevant, will be included.

Despite their unmanned nature, ROVs still require human input for control, although this can be dependent on the mode of operation [19]. Regardless of control mode, they will interact with the control room sociotechnical system as a whole. Sociotechnical systems are defined as systems consisting of interacting human and technological agents, working towards common goals [20]. A sociotechnical system can have multiple, interacting subsystems. Maritime control rooms can be classified as sociotechnical systems due to the interaction between trained operators and advanced technology [21-24]. As a less than optimally performing sub-system could affect the entire sociotechnical system [25], it is vital all aspects are sufficiently optimised. This applies to the ROV subsystem, which includes ROVs and their operators. One potential area of optimisation in the ROV subsystem is the User Interface (UI), which can be a critical success factor in command environments [26]. Whilst ROVs technology is constantly improving, their UIs may not have improved in tandem [16, 27]. As information and commands are exchanged through the UI, contributing to operator situation awareness, its effectiveness is vital to avoid incorrect information being recorded or incorrect actions being taken. Thus, it would be pertinent to explore how UIs could be designed to maintain optimal control of the ROV.

Ecological Interface Design (EID) is a design paradigm offering great potential for the optimal design of ROV interfaces. EID [28] is a design paradigm designed for sociotechnical systems of a complex nature, with the aims of supporting operators at all levels of cognitive control [29, 30]. This is achieved by capitalising on an operators innate cognitive capabilities [29]. Utilising these capabilities ensures cognitive capacity is maintained for when more complex, or unforeseen situations are encountered, enabling more effective analysis and decisions to be made when they are encountered. This paper will explore current ROV utilisation, and how EID could be applied to maximise usability and capability, while reducing cognitive workload. 


\section{Remotely Operated Vehicle Usage}

ROVs are currently being used for a wide variety of missions, with plans for their capabilities and usage to grow [3, 7], supported by a wide range of capabilities [31]. The Department of the Navy [7] identifies nine main mission types, ranging from Intelligence, Surveillance, and Reconnaissance (ISR) to Information Operations (IO). An initial usage of ROVs was for mine hunting [1]. The small profiles of ROVs enables them to navigate minefields with a reduced chance of triggering a mine compared to the parent ship, and disarm them. Furthermore, remote operation ensures that if a mine was detonated the potential for loss of life is greatly reduced. This led the US Navy to launch the Long Term Mine Reconnaissance System (LMRS), which would clear a minefield before a manned platform arrives. Mine neutralisation ROVs are typically equipped with a specialist set of tools and sensors for operators to use. The US Navy's Mine Neutralisation System (MNS) was equipped with two cable cutters, a bomblet, high resolution sonar, and a low light TV, which relays visual information back to the operator [32]. Given the nature of mine hunting, it is vital that these tools can be operated accurately and effectively. The UI must allow operators to be acutely aware of the status of these tools at all times, to maximise the ROVs utility.

ROVs are capable of being used for a variety of purposes, which can broadly be split into four major categories [31, 33]: Maritime Reconnaissance (MR), Undersea Search and Survey (USS), Communication/Navigation Aid (C/N A), and Submarine Track and Trail (ST\&T).

MR is focused on intelligence gathering that can be actioned, or passed on, such as scoping out an area of interest. While this could be carried out by ownship, Hardy and Barlow [34] argued that sending an ROV could conserve limited resources, permitting extended deployment periods. In such instances of operation the UI would be even more vital, as it would convey remote sensor information back to ownship. Incorrect interpretation of the data due to a poorly designed interface may cause ownship to take actions that it may not otherwise take, creating a dangerous situation.

USS provides the ability to conduct surveys of a vessel's surrounding area, using UUVs. This facilitates an understanding of a vessel's environment for purposes such as navigation or safety. A joint research project at the NATO Undersea Research Centre has demonstrated the usage of AUVs to successfully map an area of operation [35]. The Generic Oceanographic Array Technology Systems (GOATS) project tested various ROV configurations in different conditions, successfully mapping their operational area each time, with this information being reported back to the parent vessel. This information displayed in the UI should be understandable for navigators, and should make dangerous areas immediately apparent.

$\mathrm{C} / \mathrm{N}$ A functionality allows AUVs to communicate with each other and monitoring vessels. This extends communication ranges, ensuring that relevant information can be shared across large distances. For example, the Seaweb project facilitates communication of underwater nodes, such as vessel's or ROVs, to exchange information [36]. Receiving information from a larger area will increase the amount of data shown. Therefore, it is important that this data is displayed in an accessible manner that does not overwhelm operators.

ST\&T functionality involves tracking a submarine, and relaying information back to own ship, allowing proper tactical decisions to be made. Certain vessel's have been 
identified as being an ideal platform for delivering autonomous sensor networks that could deny undetected movements to non-allied submarines [34, 37]. This extends the area that vessels can be tracked in, ensuring that their location and intentions can be tracked more effectively. Again, this would increase data being displayed to an operator, requiring it to be displayed effectively, to avoid overload. As sensor data contributes towards maintaining safety and completion of missions, this is imperative.

\section{Ecological Interface Design}

EID is a theoretical framework for designing Human Machine Interfaces (HMIs) of a complex nature [28], with the objectives of not forcing cognitive processing to a higher level than tasks require, and supporting all levels of cognitive control by making the constraints of a system immediately apparent $[30,38]$. It has been shown to reduce workload [39] and memory requirements [29]. It is based on the Skills Rules Knowledge (SRK) Taxonomy [40] and the Abstraction Hierarchy [28, 41]. The Abstraction Hierarchy is a stratified hierarchy for describing work domains [41]. Each level represents a different level of abstraction, ranging from the physical objects (such as buttons), to its purpose for existing. Each level is linked using means-end links, which indicate how and why different parts of the system exist. Reduction of cognitive demand is achieved by displaying both Physical (representations of system components) and Functional (system structure and constraints) information, allowing the interface to take advantage of human perception and psychomotor abilities [42, 43]. EID builds on traditional interfaces (those only displaying Physical information) with the addition of Functional information, which can lead to better performance than either alone [44, 45]. For example, instead of solely displaying the amount of a vehicle's fuel remaining (Physical information), an interface could highlight an optimal path for the vehicle based on the remaining fuel level (Functional information). This removes the need for the operator to calculate the vehicle's route, conserving cognitive capacity. The SRK Taxonomy splits human behaviour into three discrete categories [40, 46]: skill based behaviour (tacit knowledge), rule based behaviour (learned responses to signals), and knowledge based behaviour (courses of action generated in response to unfamiliar situations). By understanding each level of behaviour an interface can be designed that supports all levels of ability. This would permit operators of different skill levels to successfully use the ROV; novice users could be supported via additional hints in the user interface, and expert users could configure the interface to display information congruent to their data-processing workflow. By facilitating these behaviours, operators do not need to 'work around' the interface to achieve their goals, reducing cognitive workload.

\section{Potential Application to ROVs}

ROV usage in the maritime domain is focused on extending a vessel's sensors, and understanding its environment. From mine hunting to ST\&T functionality, there is an element of understanding aspects of a vessel's environment and responding appropriately. These aims are synergistic with EID, and it is argued that future ROV interfaces should leverage these design principals [27]. This would facilitate cognitive workload 
being kept to a minimum, preserving cognitive capability for novel, or high workload situations.

Whilst ROV capabilities may be wide ranging, they typically include map views that show the current position of the vehicle, and annotations of its environment, including routing information (see figure 1). Items annotated in the environment may include areas of interest and known vessel positions (see [47-50] for examples). These map views show physical information about the environment, but do not represent functional information. For example, additional information could be provided to inform the operator as to whether they have enough fuel to reach the area of interest by marking its range using a circle, see figure $2 \mathrm{a}, \mathrm{b}$. By adding this information, a need for the operator to calculate this themselves is removed, potentially saving cognitive capacity [27]. This is further illustrated by display routes on the map. A line representing a route may sufficiently indicate a chosen path, but not provide the user with enough information to know why. This requires them to assess other information provided on the interface, incurring additional cognitive workload [27]. However, if the logic for the path choice was displayed on the interface, such as highlighting weak currents that will require less fuel to navigate in, the reasoning would be apparent, and cognitive workload could be kept to a minimum.

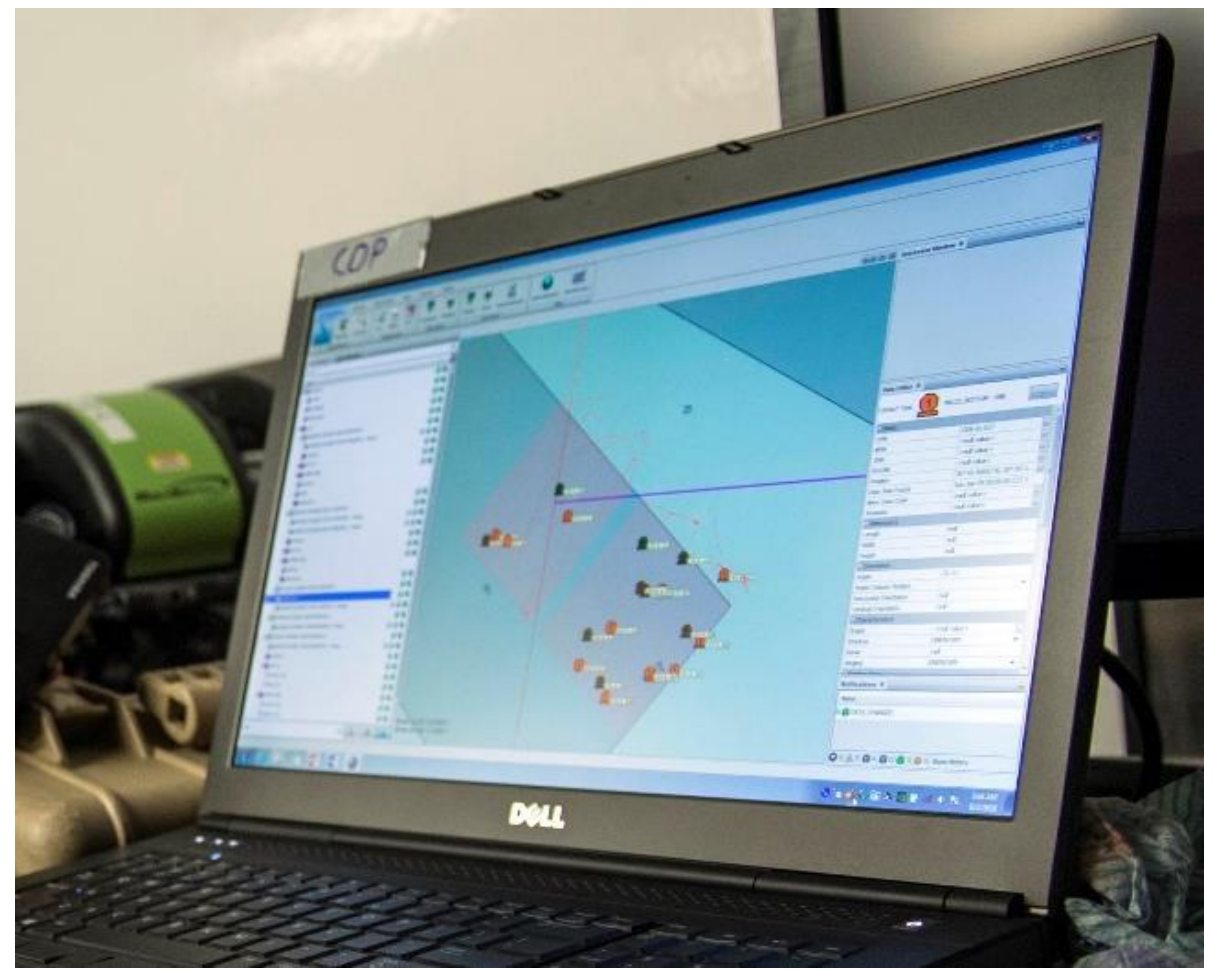

Figure 1. A sample UUV interface, being used for compiling mine detection details from collected data [51]. Note that the environment is annotated to show items of interest. 
It is likely that elements of EID already exist in ROV design. For example, the low light TV integrated into the mine sweeping ROV provides Physical visual information about its environmental constraints, which could hint at Functional information such as the sea state, water clarity, etc. Explicit Functional information about the ROV could be provided to the operator, reducing their cognitive workload by removing their need to process information. For example, if the sea state is rough, the UI could suggest manoeuvring to a calmer location. Alternatively, the direction of the last mine found could be marked. These Functional information additions could provide the operator with a better tacit understanding of their environment and its constraints, by clearly displaying information pertinent to their aims. This may alleviate issues with increased data [9], conserving cognitive capability for additional, or previously unseen, data. This spare capacity could potentially allow operators to better respond to unforeseen situations, preventing accidents.

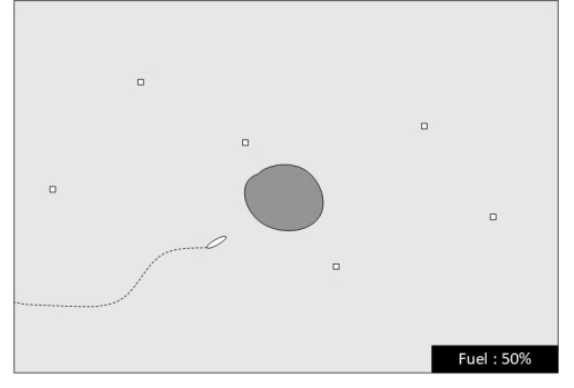

$\mathrm{a}$

Figure 2a. A generic ROV map view, showing an ROV (ellipse) heading towards an area of interest (dark circle), and known vessel positions (white squares). The ROVs' historic path is shown by the trailing dotted line. Fuel is indicated textually at the bottom right. Note that while an operator can work out how much distance they can travel, this is not afforded by the UI.



Figure $2 \mathrm{~b}$. The same generic map view, updated to include Functional fuel information. The fuel is now displayed as a meter, and the expected range is shown on the map using a circle. This removes the need for operators to calculate expected range manually, reducing cognitive workload.

\section{Conclusions}

ROVs are increasingly being used to support a wide variety of operations, in both civilian industry and the military. This is due to the fact that they can complete tasks humans may not be able to, while maintaining operator safety. Generally, their usage is successful, however incidents can still occur as a consequence of inappropriate UIs, creating an increased cognitive workload. Human factors issues have previously been identified as a causal factor, suggesting that ROV design could potentially be improved to optimise their usage. A potential specific area of improvement could be the UI, which can be a critical factor of success in command and control environments. Despite being unmanned, ROVs still require input from a human, who will act upon information returned from the vehicle, as well as typically controlling the vehicle (dependant on the mode of operations). Unsuitable UI design may cause information to be overlooked, or incorrect decisions to be taken, impairing operational capability. EID is proposed as a design paradigm to create future UIs, as its goals are synergistic 
with those of ROV operation, namely understanding an environment and its constraints. It is proposed that applying EID to an ROV interface could further support operators and their work, maximising the return on investment for ROVs. Future work will explore this possibility, assessing how to optimise the integration of increasingly more capable ROVs into a vessel's command space, whilst minimising operator cognitive workload.

\section{Acknowledgements}

This work was funded by the Defence Science and Technology Laboratory (Dstl) on behalf of the Ministry of Defence (MOD) under contract number TIN 3.228.

\section{References}

1. Wernli, R.L.: AUVs-a technology whose time has come. In: Proceedings of the 2002 Interntional Symposium on Underwater Technology (Cat. No.02EX556), pp. 309-314. (2002)

2. Ding, N., Li, Z., Yang, C., Ge, T.: Robust adaptive motion control for Remotely Operated Vehicles with velocity constraints. In: Robotics and Biomimetics (ROBIO), 2010 IEEE International Conference on, pp. 932-937. IEEE, (2010)

3. Button, R.W., Kamp, J., Curtin, T.B., Dryden, J.: A survey of missions for unmanned undersea vehicles. Rand National Defense Research Institute (2009) 4. O'Rourke, R.: Navy Virginia (SSN 774) Class Attack Submarine Procurement: Background and Issues for Congress. Congressional Research Service Washington United States (2016)

5. Eckstein, M. Navy Racing to Test, Field Unmanned Maritime Vehicles for Future Ships [Online]. Annapolis, Maryland, United States of America: United States Naval Institute. Available: https://news.usni.org/2017/09/21/navy-racing-test-fieldunmanned-maritime-vehicles-future-ships (2017)

6. Savitz, S., Blickstein, I., Buryk, P., Button, R.W., DeLuca, P., Dryden, J., Mastbaum, J., Osburg, J., Padilla, P., Potter, A.: US Navy employment options for unmanned surface vehicles (USVs). Rand National Defense Research Institute (2013) 7. Department of the Navy: The Navy Unmanned Undersea Vehicle (UUV) Master Plan. Department of the Navy (2004)

8. $\quad$ Stashwick, S. US Designing New Unmanned Vehicles to Help Its Subs Detect Adversaries [Online]. Tokyo, Japan: The Diplomat. Available:

https://thediplomat.com/2017/07/us-designing-new-unmanned-vehicles-to-help-itssubs-detect-adversaries/ (2017)

9. $\quad$ Porche, I.R., Wilson, B., Johnson, E.-E., Tierney, S., Saltzman, E.: Data

Flood: Helping the Navy Address the Rising Tide of Sensor Information. RAND Corporation (2014)

10. Williams, K.W.: A Summary of Unmanned Aircraft Accident/Incident Data: Human Factors Implications. (2004)

11. Gagnon, J.-F., Durantin, G., Vachon, F., Causse, M., Tremblay, S., Dehais, F.: Anticipating human error before it happens: Towards a psychophysiological model 
for online prediction of mental workload. Human Factors Ergonomics Society (HFES 2012) Chapter Europe, pp. pp. 57-66 (2012)

12. Ho, G., Pavlovic, N., Arrabito, R.: Human factors issues with operating unmanned underwater vehicles. In: Proceedings of the Human Factors and Ergonomics Society Annual Meeting, pp. 429-433. Sage Publications Sage CA: Los Angeles, CA, (2011)

13. National Oceanic and Atmospheric Administration. What is the difference between an AUV and an ROV? [Online]. Silver Spring, Maryland, United States of America: NOAA. Available: https://oceanservice.noaa.gov/facts/auv-rov.html (2018) 14. Christ, R.D., Wernli, R.L.: The ROV manual: A User Guide for Remotely Operated Vehicles. Butterworth-Heinemann (2013)

15. Kumar, A.M.P.S.: A Review Paper on Telecommunication and Telemetry using OFC. (2016)

16. Rubin, S.: Mini-ROVs, going where no ROV has gone before. In: 2013

OCEANS - San Diego, pp. 1-4. (2013)

17. Johnson, N., Patron, P., Lane, D.: The importance of trust between operator and auv: Crossing the human/computer language barrier. In: OCEANS 2007-Europe, pp. 1-6. IEEE, (2007)

18. Farr, N., Bowen, A., Ware, J., Pontbriand, C., Tivey, M.: An integrated, underwater optical /acoustic communications system. In: OCEANS 2010 IEEE Sydney, pp. 1-6. (2010)

19. Cooke, N.J.: Human Factors of Remotely Operated Vehicles. Proceedings of the Human Factors and Ergonomics Society Annual Meeting 50, 166-169 (2006)

20. Walker, G.H., Stanton, N.A., Salmon, P.M., Jenkins, D.P.: A review of sociotechnical systems theory: a classic concept for new command and control paradigms. Theoretical Issues in Ergonomics Science 9, 479-499 (2008)

21. Ly, T., Huf, S., Henley, P.: Design for Submarine Command and Control in the 21st Century. 12th International Command and Control Research and Technology Symposum, . DoD CCRP, Newport, Rhode Island, United States of America (2007) 22. Stanton, N.A., Bessell, K.: How a submarine returns to periscope depth: Analysing complex socio-technical systems using Cognitive Work Analysis. Applied Ergonomics 45, 110-125 (2014)

23. Stanton, N.A.: Representing distributed cognition in complex systems: how a submarine returns to periscope depth. Ergonomics 57, 403-418 (2014)

24. Stanton, N.A., Roberts, A.P.J., Fay, D.T.: Up periscope: understanding submarine command and control teamwork during a simulated return to periscope depth. Cogn Tech Work 19, 399-417 (2017)

25. Meshkati, N.: Integration of workstation, job, and team structure design in complex human-machine systems: A framework. International Journal of Industrial Ergonomics 7, 111-122 (1991)

26. Walker, G.H., Stanton, N.A., Jenkins, D.P., Salmon, P.M., Rafferty, L.: From the 6 Ps of Planning to the 4 Ds of Digitization: Difficulties, Dilemmas, and Defective Decision Making. International Journal of Human-Computer Interaction 26, 173-188 (2010)

27. Kilgore, R., Voshell, M.: Increasing the Transparency of Unmanned Systems: Applications of Ecological Interface Design. In: Virtual, Augmented and 
Mixed Reality. Applications of Virtual and Augmented Reality, pp. 378-389. Springer International Publishing, Cham (2014)

28. Vicente, K.J., Rasmussen, J.: Ecological interface design: Theoretical foundations. IEEE Transactions on Systems, Man and Cybernetics 22, 589-606 (1992)

29. Lau, N., Jamieson, G.: Ecological interface design for the condenser subsystems of a boiling water reactor. In: Proceedings of the 16th World Congress on Ergonomics. (2006)

30. McIlroy, R.C., Stanton, N.A.: Ecological Interface Design Two Decades On: Whatever Happened to the SRK Taxonomy? IEEE Transactions on Human-Machine Systems 45, 145-163 (2014)

31. Wernli, R.L.: Low cost uuv's for military applications: Is the technology ready? , Space and Naval Warfare Systems Center (2000)

32. Wernli, R.L.: Trends in UUV development within the US Navy. In:

OCEANS '97. MTS/IEEE Conference Proceedings, pp. 841-848 vol.842. (1997)

33. Fletcher, B.: UUV master plan: a vision for navy UUV development. In:

OCEANS 2000 MTS/IEEE Conference and Exhibition. Conference Proceedings (Cat. No.00CH37158), pp. 65-71 vol.61. (2000)

34. Hardy, T., Barlow, G.: Unmanned Underwater Vehicle (UUV) deployment and retrieval considerations for submarines. (2008)

35. Bovio, E., Cecchi, D., Baralli, F.: Autonomous underwater vehicles for scientific and naval operations. Annual Reviews in Control 30, 117-130 (2006)

36. Rice, J.: Seaweb Acoustic Communication and Navigation Networks Underwater Acoustic Measurements: Technologies \& Results, Heraklion, Crete, Greece (2005)

37. Stewart, M.S., Pavlos, J.: A means to networked persistent undersea surveillance. In: Submarine Technology Symposium, University of Washington, Tacoma, Wash. (2006)

38. Vicente, K.J., Christoffersen, K., Pereklita, A.: Supporting operator problem solving through ecological interface design. Systems, Man and Cybernetics, IEEE Transactions on 25, 529-545 (1995)

39. Nielsen, C.W., Goodrich, M.A., Ricks, R.W.: Ecological Interfaces for Improving Mobile Robot Teleoperation. IEEE Transactions on Robotics 23, 927-941 (2007)

40. Rasmussen, J.: Skills, rules, and knowledge; signals, signs, and symbols, and other distinctions in human performance models. IEEE Transactions on Systems, Man and Cybernetics 257-266 (1983)

41. Vicente, K.J.: Cognitive Work Analysis: Toward safe, productive, and healthy computer-based work. CRC Press, Mahwah, USA (1999)

42. Dinadis, N., Vicente, K.J.: Ecological interface design for a power plant feedwater subsystem. Nuclear Science, IEEE Transactions on 43, 266-277 (1996) 43. Pawlak, W.S., Vicente, K.J.: Inducing effective operator control through ecological interface design. International Journal of Human-Computer Studies 44, 653-688 (1996)

44. Torenvliet, G.L., Jamieson, G.A., Vicente, K.J.: Making the most of ecological interface design: the role of individual differences. Applied Ergonomics $31,395-408$ (2000) 
45. Vicente, K.J.: Ecological interface design: Progress and challenges. Human Factors: The Journal of the Human Factors and Ergonomics Society 44, 62-78 (2002) 46. McIlroy, R.C., Stanton, N.A.: A decision ladder analysis of eco-driving: the first step towards fuel-efficient driving behaviour. Ergonomics 58, 866-882 (2015) 47. Hagen, P.E.: AUV/UUV mission planning and real time control with the HUGIN operator system. In: MTS/IEEE Oceans 2001. An Ocean Odyssey. Conference Proceedings (IEEE Cat. No.01CH37295), pp. 468-473 vol.461. (2001) 48. Willcox, S., Goldberg, D., Vaganay, J., Curcio, J.: Multi-vehicle cooperative navigation and autonomy with the bluefin CADRE system. (2006)

49. Kinsey, J.C., Whitcomb, L.L.: Preliminary field experience with the DVLNAV integrated navigation system for oceanographic submersibles. Control Engineering Practice 12, 1541-1549 (2004)

50. Stewart, A., Ryden, F., Cox, R.: An interactive interface for multi-pilot ROV intervention. In: OCEANS 2016 - Shanghai, pp. 1-6. (2016)

51. United States Navy. 160802-N-WB378-102 [Online]. Washington, D.C, United States of America: United States Navy,. Available:

http://www.navy.mil/view_image.asp?id=223151 (2016) 